\title{
Sequential Investments and Options to Own
}

\author{
Georg Nöldeke* \\ Universität Basel \\ Klaus M. Schmidt** \\ Universität München and CEPR
}

First version: November 1996

This version: March 1998

\begin{abstract}
Contingent ownership structures are prevalent in joint ventures. This paper offers an explanation based on the investment incentives provided by such an arrangement. We consider a hold-up problem in which two parties make relationshipspecific investments sequentially in order to generate a joint surplus in the future. In our model, the following ownership structure implements first best investments: one party owns the firm initially, while the other party has the option to buy the firm at a set price at a later date. This result is robust to the possibility of renegotiation and uncertainty.
\end{abstract}

JEL CLASSIFICATION NUMBERS: D23, G32, L22.

Keywords: Options, Convertible Securities, Property Rights, Incomplete Contracts.

*Abteilung Wirtschaftstheorie, WWZ, Universität Basel, Petersgraben 51, CH-4003 Basel, Schweiz, Tel.: +41-61-267 3347, email: noeldeke@ubaclu.unibas.ch.

** Department of Economics, Universität München, Ludwigstr. 28 (Rgb.), D-80539 München, Germany, Tel.: +49-89-2180 2250, email: klaus.schmidt@lrz.uni-muenchen.de.

We are grateful to Glenn Ellison, Georg Gebhardt, Klaus Sandmann, Jean Tirole, and two anonymous referees for many helpful comments and suggestions. The first author would like to thank the Center for Economic Studies (CES) at the University of Munich for its hospitality. Financial support by Deutsche Forschungsgemeinschaft through grant SCHM1196/2-1 is gratefully acknowledged. 


\section{Introduction}

This paper offers a new explanation for the use of contingent ownership structures in joint ventures. Suppose that two parties, $A$ and $B$, want to set up a firm and have to agree on how to allocate ownership and control rights. Customary ownership structures are that $A$ owns and controls the firm, that $B$ owns it, or that there is some form of joint ownership. We consider slightly more complicated, contingent ownership structures. $A$, say, could own the firm initially, but $B$ is given the option to buy the firm at a predetermined price at some later date. We show that if the parties have to make relationship-specific investments and if they invest sequentially, then such an option may suffice to induce both parties to invest efficiently.

The use of contingent ownership structures, in particular of warrants and convertible securities, is prevalent in joint ventures. A warrant is an option to purchase a set number of common shares at a set price on or before a set date. For example, in January 1997, Arcor, a new telecommunications company, was set up by Deutsche Bahn (German Rail) and a consortium of Mannesmann, AT\&T, and Unisource. Initially, Deutsche Bahn controls $50.2 \%$ of Arcor's common stock. But the consortium of Mannesmann, AT\&T and Unisource has an option to increase its stockholding in 1999 at a predetermined price to $74.9 \%$ (see Frankfurter Allgemeine Zeitung, January 24, 1997, No. 20, p. 22). Convertible debt is a package of a debt contract and a warrant. The holder of convertible debt has the right to give up his bond in exchange for common stock at a set conversion price. In his extensive field study Sahlman (1990) reports that the use of convertible debt and other convertible securities is common to nearly all venture capital financing. What is the rationale for such an option to control a firm in the future?

In our model, the basic idea of an option-to-own contract is the following. Suppose that the two parties have to make relationship-specific investments sequentially. For example, $A$ may have to invest in the development of a new product or a new production technology. Thereafter, $B$ may have to invest in the marketing of the good that is going to be produced by the firm. Suppose that $A$ owns the firm initially, but that $B$ has the option to buy it after $A$ 's investment has been made but before the surplus is being realized. The more $A$ invested, the higher is $B$ 's valuation for the firm. Thus, $B$ will exercise his option if and only if $A$ 's investment is sufficiently high. If the option price is chosen appropriately, $B$ will buy the firm 
if and only if $A$ invested at least the efficient amount.

This in turn induces $A$ to invest efficiently. First, if $A$ invests too little, $B$ will not exercise his option, $A$ foregoes the option price and remains the owner the firm. Because $B$ 's investment incentives are diluted when $A$ owns the firm, the firm is not worth very much to $A$. In particular, we assume that $B$ will not invest at all when $A$ is the owner, ensuring that $A$ prefers not be stranded with the firm and invests at least the efficient amount. Second, $A$ is not going to overinvest either. Since $B$ becomes the owner whenever $A$ invests at least the efficient amount, $B$ will get most of the marginal benefits if $A$ invests too much. Thus, there is no incentive for $A$ to overinvest. Finally, if - as we assume - $B$-ownership is sufficient to induce $B$ to invest efficiently, then an option contract implements the first best. ${ }^{1}$

Our analysis follows the seminal paper by Grossman and Hart (1986) and the literature on incomplete contracts ${ }^{2}$ in assuming that the only long-term contracts that can be written are contracts on ownership rights. ${ }^{3}$ For the case of simultaneous investment decisions Grossman and Hart show that there is no unconditional ownership contract that induces both parties to invest efficiently. The same result obtains in our model with sequential investments (Proposition 1). Grossman and Hart do not consider conditional ownership structures even though they

\footnotetext{
${ }^{1}$ We can relate this story to the example of Arcor given above. Before Arcor can compete successfully with Deutsche Telekom on the newly liberalized German telecommunications market, huge investments have to be made. The role of Deutsche Bahn is to build up a new cable network along its railroad lines. This alone requires an investment of DM 4-5 billion. The Mannesmann consortium brings in its technological and marketing expertise in telecommunications. It has to set up the product line and to develop the customer base. By giving Mannesmann the option to buy a controlling stake in Arcor in 1999, Deutsche Bahn has a strong incentive to invest efficiently. The more Deutsche Bahn invests, the more valuable is Arcor for Mannesmann. Thus, only if Deutsche Bahn invests sufficiently, it is worthwhile for Mannesmann to exercise its option. If Mannesmann does not exercise the option, Deutsche Bahn is left with its cable network, which is worth much less to her without the cooperation of Mannesmann. Finally, in the long-run it is clearly efficient that the Mannesmann consortium with its expertise in running telecommunications companies should own and control Arcor which is also achieved by the option contract.

${ }^{2}$ See Hart (1995, ch. 2-4) and Tirole (1994) for excellent surveys of this literature.

${ }^{3}$ This should be viewed as a simplifying assumption, meant to capture the idea that only incomplete contracts can be written so that the allocation of ownership rights retains an important role in providing appropriate investment incentives. In the context of the Arcor example, this seems quite likely. Rapid technological progress and frequent regulatory changes in the telecommunications industry make it very difficult to write a complete contingent contract on the required investments. Furthermore, Deutsche Bahn is also modernizing its railway network and probably has some discretion in shifting investment costs from its railway business to the telecommunication network. Similarly, Mannesmann runs its own celular phone network already and may have some discretion in shifting profits between these two businesses, thus limiting the scope to provide incentives by contracts that condition on profits.
} 
do mention the possibility of options on ownership. ${ }^{4}$ Our results show that with sequential investment decisions option-to-own contracts can induce both parties to invest efficiently.

The formal structure of our model is quite similiar to the ones in Demski and Sappington (1991) and Edlin and Hermalin (1997). Both of these papers consider a principal-agent model with a sequential double moral hazard problem. Demski and Sappington show that an option contract that gives the principal the right to sell his firm to the agent at a predetermined price induces both parties to choose the efficient level of effort. Furthermore, since the option will not be exercised in equilibrium, the first best can be implemented even if the agent is risk averse. Edlin and Hermalin (1997, Section 3) point out that the contract suggested by Demski and Sappington is not robust to renegotiation. They show that if renegotiation cannot be prohibited, then an option contract (with a different option price) can implement the first best if and only if investments are substitutes at the margin. It is important to note that they consider only the case where the option has to be exercised after the agent but before the principal invested. We show that if the exercise date of the option is delayed until after both parties invested, then the first best can be implemented with renegotiation even if investments are complements at the margin. Furthermore, Edlin and Hermalin restrict attention to the case where the owner of the firm captures all the benefits of the investments while we allow for more general payoff functions. On the other hand, Edlin and Hermalin consider the case where one of the two parties is risk averse, while we restrict attention to risk neutral players. ${ }^{5}$

Nöldeke and Schmidt (1996) and Maskin and Tirole (1996, Section 3) also consider options on asset ownership. Our present work generalizes the simple example with one-sided investments that we considered in Nöldeke and Schmidt (1996). Maskin and Tirole (1996) consider an example in which both parties jointly own the firm initially. After (simultaneous) investments have been made, each party gets with probability 0.5 the right to sell its shares to the other party at a predetermined price in which case the other party has to pay a fine to an outsider. The option will only be exercised if one party failed to invest efficiently. However, off the equilibrium path a fine has to be paid to an outsider. Hence the contract is not renegotiation-proof.

\footnotetext{
${ }^{4}$ See Grossman and Hart (1986), Footnote 13. Hart (1995, Chapter 4) shows that an option-to-own contract improves upon a simple ownership structure, although it cannot achieve the first best in his example.

${ }^{5}$ Edlin and Hermalin's main result for the risk-neutral case corresponds to our Proposition 5. The two papers have been written independently and almost at the same time.
} 
Our paper is also related to Aghion, Dewatripont and Rey (1994), Chung (1991), Edlin and Reichelstein (1996), Hart and Moore (1988), Hermalin and Katz (1994), and Nöldeke and Schmidt (1995). In these papers long-term contracts on trade between the two parties are feasible, but whether trade is efficient depends on the realization of a complex state of the world that cannot be contracted upon. Most of these papers demonstrate that "simple" long-term contracts on trade can induce first best investments in various contexts. In particular, Nöldeke and Schmidt (1995) show that an option contract that gives one of the parties the right (but not the obligation) to trade the good at a predetermined price can induce both parties to invest efficiently. In the present paper the option is not an option to trade, but rather an option on asset ownership. Thus, there is no need to specify the good to be traded in the initial contract. Furthermore, all of the above mentioned papers restrict attention to self-investments, i.e., the "seller" invests in reducing her costs, while the "buyer" invests in his valuation of the good. In contrast, the work presented here allows for direct externalities of both investments. In this sense, we allow for the possibility that investments are "cooperative" as in Che and Hausch (1996). ${ }^{6}$ Finally, we do not use the initial contract to allocate the bargaining power at the renegotiation stage. In our paper the allocation of bargaining power is given exogenously. ${ }^{7}$

The remainder of the paper is organized as follows. Section 2 describes the model. Section 3 restricts attention to the case where the parties cannot renegotiate the initial contract. First, it is shown that no unconditional ownership structure can implement the first best. Then we consider options on asset ownership and show that such contracts can induce both parties to invest efficiently. Section 4 allows for renegotiation and shows that our main result still holds: option contracts allow to achieve efficiency under the same conditions as in the norenegotiation case. Furthermore, we show that with renegotiation the timing of the option becomes important. $B$ must not be able to commit not to exercise his option before he

\footnotetext{
${ }^{6}$ We are grateful to one of the referees for pointing out this connection. The main difference to Che and Hausch (1996) is that they assume that investments have no value if there is "no trade", while in our model investments are always beneficial.

${ }^{7}$ In the context of long-term trade relationships, the hold-up problem with sequential investments has been considered by De Fraja (1995) and Dearden and Klotz (1995). De Fraja considers the case where the first party, $A$, has to invest before she is locked in with $B$. Because there are many potential $B$ s competing to form a joint venture with $A, A$ 's investment is not relationship-specific, so she will invest efficiently. Thus, we are essentially left with a one-sided investment problem for $B$ which can be solved by an at will contract à la Hart and Moore (1988). Dearden and Klotz simply assume that the initial contract can allocate the bargaining power between the two parties such that at different stages of the relationship first $A$ has all the bargaining power and then $B$. With sequential investments this induces both parties to invest efficiently.
} 
invested. We discuss how this might be achieved. In Section 5 we introduce uncertainty into the model and show that options on asset ownership still implement the first best if the uncertainty is sufficiently small. Section 6 concludes.

\section{The model}

Consider two parties, $A$ and $B$, who can generate a surplus $v(a, b) \geq 0$ at some future date 3 . The surplus can only be produced with a physical asset. ${ }^{8}$ The amount of the surplus depends on relationship-specific investments $a, b \in \mathbb{R}_{0}^{+}$that have to be made by $A$ and $B$, respectively. The case of multidimensional investments is briefly discussed after Proposition 2. Investments are measured by their costs. Thus, the ex ante surplus is given by

$$
S(a, b)=v(a, b) \Leftrightarrow a \Leftrightarrow b
$$

Investments take place sequentially, i.e. $A$ invests at date 1 , the level of her investment is observed by $B$, who then has to invest at date 2 . We assume that $v(a, b)$ is positive, continuously differentiable, strictly increasing in both arguments, strictly concave, and satisfies for all $a, b \in \mathbb{R}_{0}^{+}$:

$$
\lim _{a \rightarrow \infty} v_{a}(a, b)<1, \lim _{b \rightarrow \infty} v_{b}(a, b)<1
$$

and

$$
v_{a}(0, b)>1, v_{b}(a, 0)>1,
$$

where subscripts denote partial derivatives. Under these assumptions the first best investment levels

$$
\left(a^{*}, b^{*}\right) \in \arg \max _{a, b} v(a, b) \Leftrightarrow a \Leftrightarrow b \gg(0,0)
$$

are uniquely defined and satisfy the first order conditions

$$
v_{a}\left(a^{*}, b^{*}\right)=v_{b}\left(a^{*}, b^{*}\right)=1 .
$$

For later reference it will be convenient to let $b^{*}(a)$ denote the efficient investment level by $B$ given that $A$ has chosen $a$. This function is implicitly defined by the first order condition

$$
v_{b}\left(a, b^{*}(a)\right)=1 \text {. }
$$

\footnotetext{
${ }^{8}$ The physical asset may be a plant, machinery, a building, but also a "soft" asset such as a patent or a client list. Of course, the asset could also be a set of perfectly complementary assets in which case we would call it a firm. The only important property is that ownership and control of the asset can be given to either party. See Hart (1995, p. 56ff).
} 
Note that $v\left(a, b^{*}(a)\right)$ is strictly concave in $a$.

In discussing our results and assumptions, we will make reference to the following additional properties that the value of the asset may satisfy. Investments are said to be independent when $v_{a b}(a, b)=0$ holds for all $(a, b) .{ }^{9}$ If a larger investment by party $i$ increases the marginal benefit of $j$ 's investment, i.e. for all $(a, b), v_{a b}(a, b)>0$, investments are complements at the margin. If the reverse strict inequality holds, investments are substitutes at the margin.

At date 0 the two parties can write a contract governing their relationship. The only contracts we consider are contracts that allocate ownership and control rights on the physical asset at date $t=3$. For example, the initial contract could say that $A$ owns the asset, that $B$ owns it, or that there is joint ownership (in which case the consent of both parties is required to generate the surplus). We will use the letter $o \in\{A, B, J\}$ to denote such an unconditional allocation of ownership rights. Here $o=A$ denotes $A$-ownership, $o=B$ denotes $B$ ownership, and $o=J$ denotes joint ownership. We also allow for slightly more complicated allocations of ownership rights. In particular, one party, say $A$, could own the asset initially, but $B$ is given the option to buy the asset at a fixed price $p$ at some date $t$ that has to be specified in the contract. ${ }^{10}$ We will show that such an option contract can be used to implement the first best investment levels in many interesting cases. This is why we will not consider more complicated conditional ownership arrangements. The initial contract can also specify unconditional sidepayments which can be used to adjust the sharing of the total surplus between the two parties in any desired fashion. In order to save on notation we do not consider such side-payments explicitly.

Given the allocation of ownership rights in place at date 3, there may be a need for the parties to bargain over the use of the asset to realize the full surplus $v(a, b)$. We assume that bargaining, which takes place under symmetric information, always results in an efficient

\footnotetext{
${ }^{9}$ An interesting case in which investments may be taken to be independent, is the one in which the asset is used to produced an indivisible commodity and $A$ 's investment lowers the cost of producing the output with the asset, whereas $B$ 's investment increases a customer's valuation of the output. This is captured by setting $v(a, b)=u(b)-c(a)$.

${ }^{10}$ Note that an option to own is not conditional on the investment of one party or on the realization of a complicated state of the world. It simply says that the ownership right is transferred from $A$ to $B$ if $B$ makes a certain payment at a date $t$ to be specified in the contract. This can be verified easily by the courts and the feasibility of such a contract is consistent with the arguments presented in Grossman and Hart (1986), Hart and Moore (1990) or Hart (1995).
} 
use of the asset, no matter how ownership rights are allocated. ${ }^{11}$ How the surplus is shared depends on the allocation of ownership rights and the nature of the investments made by the two parties because these factors determine the threatpoint in the bargaining over the use of the asset.

In particular, let $U^{A}(a, b \mid o)$ and $U^{B}(a, b, \mid o)$ denote the final payoffs (inclusive investment costs, but ignoring any payments made before date 3) of $A$ and $B$, respectively, given investment levels $a$ and $b$ and a feasible ownership structure $o \in\{A, B, J\}$. We assume that these payoffs are given by

$$
U^{A}(a, b \mid o)= \begin{cases}v(a, \beta b)+\lambda[v(a, b) \Leftrightarrow v(a, \beta b)] \Leftrightarrow a & \text { if } o=A \\ \lambda[v(a, b) \Leftrightarrow v(\alpha a, b)] \Leftrightarrow a & \text { if } o=B \\ \lambda v(a, b) \Leftrightarrow a & \text { if } o=J\end{cases}
$$

and

$$
U^{B}(a, b, \mid o)= \begin{cases}(1 \Leftrightarrow \lambda)[v(a, b) \Leftrightarrow v(a, \beta b)] \Leftrightarrow b & \text { if } o=A \\ v(\alpha a, b)+(1 \Leftrightarrow \lambda)[v(a, b) \Leftrightarrow v(\alpha a, b)] \Leftrightarrow b & \text { if } o=B \\ (1 \Leftrightarrow \lambda) v(a, b) \Leftrightarrow b & \text { if } o=J\end{cases}
$$

where $\alpha \in[0,1], \beta \in[0,1]$, and $\lambda \in(0,1)$ are exogenous parameters.

These payoff functions reflect the following considerations. First, investment costs have been sunk before date 3 so that the allocation of ownership rights only affects how the value $v(a, b)$ is split between the parties. Second, the threatpoint in the bargaining game at date 3 is given by the payoff each party can realize on its own. These payoffs are taken to be $(v(a, \beta b), 0)$ in the case of $A$ ownership, $(0, v(\alpha a, b))$ in the case of $B$ ownership and $(0,0)$ in the case of joint ownership. Third, the remaining surplus is split according to the generalized Nash-bargaining solution in proportion $(\lambda, 1 \Leftrightarrow \lambda)$ between $A$ and $B$. Note that we assume $\lambda$ to be independent of the ownership arrangement.

What is the interpretation of the threatpoints? If one party has an ownership right on the physical asset, it can prevent the other party from using the asset. Since the asset is essential for realizing any surplus, a party that does not control the asset gets a payoff of 0 if there is no cooperation. Joint ownership means that each party can block the other party from using the asset, so in this case both parties receive 0 if negotiation breaks down.

\footnotetext{
${ }^{11}$ We thus follow the standard assumption in the incomplete contracting literature that contracts on the usage of the asset are feasible once all investment decisions have been made, but are not feasible prior to that date.
} 
If there is $A \Leftrightarrow$ or $B \Leftrightarrow$ ownership, the threatpoint to an owner depends on the nature of the investments. It is useful to distinguish between investments in physical and in human capital. An investment in physical capital is embodied in the physical asset. Thus, whoever owns the asset can make full use of the investment even without the cooperation of the other party. In contrast, if the investment is in human capital, then the investment is worthless to the owner of the physical asset if there is no cooperation with the investor at date 3. Obviously, an owner will always cooperate with himself, hence it does not matter whether the owner's investment is in physical or human capital. In the above specification of the payoff functions, the case $\alpha=1$ thus corresponds to $A$ investing in physical capital, whereas the case $\alpha=0$ corresponds to $A$ investing in human capital. Similarily, $\beta=1$ means that $B$ invests in physical capital, whereas $\beta=0$ means that $B$ invests in human capital. Less extreme cases are captured by allowing $\alpha$ and $\beta$ to take values in the interval $[0,1]$. Note that the agents do not choose the nature of their investments which are given exogenously.

Obviously, the above payoff functions satisfy the condition

$$
S(a, b)=U^{A}(a, b \mid o)+U^{B}(a, b \mid o) .
$$

for all $a, b$, and $o$, capturing our assumption that bargaining leads to ex-post efficiency. Because $v(a, b)$ is strictly concave in $b, B$ 's optimal investment given the ownership structure $o \in\{B, J\}$ and $A$ 's investment $a$ at date 1 is uniquely determined. Whenever $B$ 's optimal investment is unique, we denote it by

$$
b(a \mid o)=\arg \max _{b} U^{B}(a, b \mid o) .
$$

Given our informational assumptions and the time structure of the investment decisions, any of the initial contracts on ownership rights we will consider gives rise to payoff functions for the two players and defines an extensive form game in a straightforward manner. Whenever we say that an initial contract "induces" or "implements" efficient investment levels, we mean that in the unique subgame perfect equilibrium of the game corresponding to the initial contract the efficient investment choices $\left(a^{*}, b^{*}\right)$ are made on the equilibrium path. Correspondingly, the first best cannot be induced (or implemented) under a given initial contract if there exist no equilibrium in the resulting game in which the efficient choices are made on the equilibrium path. 
Figure 1 summarizes the time structure of the model.

\begin{tabular}{|c|c|c|c|}
\hline 0 & 1 & 2 & 3 \\
\hline $\begin{array}{l}\text { contract on } \\
\text { allocation of } \\
\text { wnership rights }\end{array}$ & $\begin{array}{c}A \text { invests } \\
a\end{array}$ & $\begin{array}{c}B \text { invests } \\
b\end{array}$ & $\begin{array}{l}\text { bargaining, } \\
v(a, b) \\
\text { realized }\end{array}$ \\
\hline
\end{tabular}

FiguRE 1: Time structure of the model

\section{Option contracts without renegotiation}

To illustrate our main idea, we start with the simplest case where the contract on asset ownership cannot be renegotiated. Consider first "standard" ownership contracts, that allocate ownership rights unconditionally, i.e. the initial contract specifies either $A$-ownership, $B$ ownership or joint ownership. In their seminal paper, Grossman and Hart (1986) observed that with simultaneous investments there is no such standard ownership structure that induces both parties to invest efficiently. ${ }^{12}$ Our first proposition adapts this result to our framework with sequential investments. As in a model with simultaneous investments, the crucial observation is that at least one party does not get the full marginal return of its investment at $\left(a^{*}, b^{*}\right)$. A slight complication arises in our sequential set-up because, by moving first, A can affect B's investment decision through her investment level.

Proposition 1 No unconditional allocation of ownership rights induces first best investments.

ProOF: Suppose that the allocation of ownership rights $o$ does implement first best investment levels. Because $B$ 's payoff function is differentiable in $b$, it then must be the case that

$$
U_{b}^{B}\left(a^{*}, b^{*} \mid o\right)=0 .
$$

\footnotetext{
${ }^{12}$ The Grossman and Hart model is slightly more complicated than the simplified model considered here. In particular, Grossman and Hart have two assets. Thus, $A(B)$-ownership in our model corresponds to $A(B)$ integration in their model, while joint ownership can be associated with non-integration. Furthermore, the threatpoint of negotiation in their model is the Nash equilibrium of an explicit game being played at date 3, so their investments can have a more general effect on the two parties' outside options than in our model. However, an argument as in the proof of Proposition 1 shows that the main result of Grossman and Hart is not affected by these simplifications.
} 
holds. Since $\lambda>0$ we have $U_{b}^{B}\left(a^{*}, b^{*} \mid A\right) \leq U_{b}^{B}\left(a^{*}, b^{*} \mid J\right)<S_{b}\left(a^{*}, b^{*}\right)=0$. Thus, (11) implies $o=B$. Because bargaining at date 3 is ex post efficient under any ownership structure (eqn. (9)) ,

$$
S_{b}\left(a^{*}, b^{*}\right)=U_{b}^{A}\left(a^{*}, b^{*} \mid o\right)+U_{b}^{B}\left(a^{*}, b^{*} \mid o\right)=0
$$

holds as an identity. Equations (11), (12), and $o=B$ imply

$$
U_{b}^{A}\left(a^{*}, b^{*} \mid B\right)=0
$$

Consider now $A^{\prime}$ 's optimal investment decision. Because $b^{*}=b\left(a^{*} \mid B\right)>0$, the function $b(a \mid B)$ is differentiable at $a^{*}$. The first order condition for the choice of $a^{*}$ then requires

$$
U_{a}^{A}\left(a^{*}, b^{*} \mid B\right)+U_{b}^{A}\left(a^{*}, b^{*} \mid B\right) \cdot b_{a}\left(a^{*} \mid B\right)=0
$$

and hence by (13)

$$
U_{a}^{A}\left(a^{*}, b^{*} \mid B\right)=0
$$

Since $\lambda<1$ implies $U_{a}^{A}\left(a^{*}, b^{*} \mid B\right)<S_{a}\left(a^{*}, b^{*}\right)=0$, this is impossible.

While we do not attempt to derive the "optimal" unconditional ownership structure, some remarks on the distortions caused by the various arrangements are worth making. If investments are independent there is no direct externality of the investments. ${ }^{13}$ In particular, with independent investments it is possible to induce one party to invest efficiently by making this party the sole owner of the asset. The other party, however, will underinvest (with joint ownership both parties will underinvest). If the investments are complements, then both parties would underinvest as compared to $\left(a^{*}, b^{*}\right)$ under any unconditional ownership structure if investments were simultaneous. This is the case usually considered in the literature. With sequential investments matters are more complicated because an additional investment incentive for $A$ arises due to the effect her investment choice has on the subsequent investment choice by $B$. Below we will consider the case in which $B$ 's investment incentives under $A$ ownership are sufficiently low to ensure that $B$ will never invest under $A$ ownership. In this case $A$ will surely underinvest if she owns the asset and investments are complements. If investments are substitutes, it may happen (both in the model with sequential investments

\footnotetext{
${ }^{13}$ But there is of course an indirect externality in that investments increase the total surplus that is being shared in the bargaining game at date 3 .
} 
considered here and with simultaneous investments) that one party overinvests. The intuition is straightforward. Suppose that investments are substitutes and that $A$ owns the asset. If $A$ anticipates that $B$ is going to invest very little (e.g. because his investment is in physical capital in which case he will not invest at all), then the marginal return of $A$ 's investment is very high. Thus, if she can appropriate the full marginal return of her investment, she will invest too much as compared to $a^{*}{ }^{14}$

Consider now a slightly more complicated ownership structure. Suppose that $A$ owns the asset initially, but that $B$ gets the option to buy it at price $p$ at date $2 \frac{1}{2}$, i.e., after both investments have been made. ${ }^{15}$ We show that such an option contract suffices to implement the efficient investment decision if the following assumption holds.

Assumption 1 For all a, B's optimal investment decisions satisfy

(a) $b(a \mid B)=b^{*}(a)$

(b) $b(a \mid A)=0$.

Assumption 1 requires that $B$, when owning the asset, makes the conditionally efficient investment, and that $B$ does not invest under $A$ ownership. We impose this assumption throughout the remainder of this paper. The following proposition shows how to induce efficient investments with an option-to-own contract:

Proposition 2 An option contract, giving $B$ the right to buy the asset at price

$$
p^{*}=U^{B}\left(a^{*}, b^{*} \mid B\right)
$$

after both investments have been made, induces first best investment levels $\left(a^{*}, b^{*}\right)$.

\footnotetext{
${ }^{14}$ Note too, that if both parties invest in physical capital, then joint ownership may outperform both $A$ and $B$-ownership. The reason is that $A$ will not invest at all if $B$ owns the asset, while $B$ will not invest at all if $A$ owns the asset. If it is important that both parties invest a positive amount, joint ownership, which provides both parties with some incentive to invest, may be a good idea - in particular, if the investments are complements at the margin. In contrast, joint ownership is never optimal if both parties have to invest in human capital, investments take place simultaneously, and are complements at the margin. If we give one of the parties full ownership of the asset, then the investment incentives of both parties are improved. For a further discussion of this point see Hart (1995, p. 48).

${ }^{15}$ Note that an option contract with $p=\infty$ corresponds to unconditional $A$-ownership, while an option contract with $p=0$ is equivalent to unconditional $B$-ownership.
} 
Proof: Suppose $A$ chooses $a^{*}$. If $B$ does not want to exercise the option, he should not invest (by Assumption 1(b)) and receives an overall payoff of 0 . On the other hand, if he is going to exercise his option, he should invest efficiently (by Assumption 1(a)) and receive

$$
u^{B}\left(a^{*}, b^{*}\right)=U^{B}\left(a^{*}, b^{*} \mid B\right) \Leftrightarrow p^{*}=0 .
$$

Hence, given $a^{*}$ it is optimal for $B$ to invest efficiently and to exercise his option. ${ }^{16}$ The resulting payoff for $A$ is given by

$$
u^{A}\left(a^{*}, b^{*}\right)=p^{*}+U^{A}\left(a^{*}, b^{*} \mid B\right)=S\left(a^{*}, b^{*}\right)
$$

$B$ can always guarantee himself a payoff of 0 by not investing and not exercising his option. Hence, given that $A$ invested $a, B$ 's continuation payoff, $u^{B}(a)$, satisfies $u^{B}(a) \geq 0$. If $A$ chooses $a \neq a^{*}$ her continuation payoff, $u^{A}(a)$, thus satisfies

$$
u^{A}(a) \leq u^{A}(a)+u^{B}(a) \leq \max _{b} S(a, b)<S\left(a^{*}, b^{*}\right)
$$

Consequently, $a=a^{*}$ is the uniquely optimal choice for $A$.

The idea of an option contract is very simple: The option price is chosen such that it is worth $B$ 's while to exercise his option and to invest efficiently if $A$ invested $a^{*}$. On the other hand, if $A$ chooses $a^{*}$ and receives $p^{*}$, her final payoff equals the maximum social surplus. Since $B$ 's final payoff cannot be negative in equilibrium, $a^{*}$ must be the unique optimal choice for $A$.

It is worth noting that $B$ 's payoff under $B$-ownership is strictly increasing in $a$, which is not used in the proof but which can easily be shown by using Assumption 1(a). If $A$ invests $a^{*}, B$ is just indifferent whether or not to exercise his option. Thus, if $A$ invests less than $a^{*}$, $B$ will choose not to become the owner and $A$ thus remains the owner of the asset. Due to Assumption 1(b) the asset will be worth very little to $A$ in this case, since $B$ chooses $b=0$. This ensures that $A$ is always better off by investing $a^{*}$ and getting the option price than by investing less than $a^{*}$, not getting the option price and being stranded with the asset. On

\footnotetext{
${ }^{16}$ Here and throughout the following analysis we suppose that $B$ exercises his option if doing so is part of an optimal strategy for him. Formally, this is justified by the fact that an optimal investment choice for $A$ does not exist if $B$ fails to exercise his option when he is indifferent. Hence, in every subgame perfect equilibrium $B$ has to exercise if he is indifferent.
} 
the other hand, if $A$ chooses $a>a^{*}, B$ will exercise his option. Since $B$ 's payoff under $B$ ownership increases with $a$ while total surplus decreases, $A$ 's payoff must also be a decreasing function of $a$ for $a>a^{*}$.

Assumption 1 is strong. We thus discuss the underlying conditions under which it is satisfied, and how it may be relaxed.

Assumption 1 holds if both parties invest in physical capital. In this case payoffs are given by

$$
\begin{aligned}
U^{A}(a, b \mid o) & = \begin{cases}v(a, b) \Leftrightarrow a & \text { if } o=A \\
\Leftrightarrow a & \text { if } o=B\end{cases} \\
U^{B}(a, b \mid o) & = \begin{cases}\Leftrightarrow b & \text { if } o=A \\
v(a, b) \Leftrightarrow b & \text { if } o=B\end{cases}
\end{aligned}
$$

corresponding to the payoff functions in the risk neutral case in Demski and Sappington (1991) and Edlin and Hermalin (1997). Assumption 1(a) is also satisfied if investments are independent, i.e., if $v_{a b}=0$. Assumption $1(\mathrm{~b})$ is satisfied whenever $B$ 's bargaining power is sufficiently low or the physical capital component of his investment is sufficiently high. To see this note that $B$ 's marginal return under $A$-owership is given by

$$
(1 \Leftrightarrow \lambda)\left[v_{b}(a, b) \Leftrightarrow \beta v_{b}(a, \beta b)\right] \leq(1 \Leftrightarrow \lambda)(1 \Leftrightarrow \beta) v_{b}(a, b)
$$

Thus, Assumption 1(b) holds whenever

$$
(1 \Leftrightarrow \lambda)(1 \Leftrightarrow \beta) v_{b}(a, 0)<1
$$

Under Assumption 1(a) it is always possible to find an option contract such that it is optimal for $B$ to invest $b^{*}$ and exercise his option if $A$ has invested $a^{*}$. It suffices to set $p^{*}=U^{B}\left(a^{*}, b^{*} \mid B\right) \Leftrightarrow \max _{b} U^{B}\left(a^{*}, b \mid A\right)$. In fact, this is the only implication of Assumption 1(a) used in the proof of Proposition 2. This condition must be satisfied if a simple option contract is to induce efficient investments. If more complicated contracts are considered, it may be relaxed (see Section 6).

Assumption 1(b) guarantees that $A$ cannot benefit from investing less than $a^{*}$. In many cases efficient investment decisions can be implemented with an option contract even though Assumption 1(b) fails. Suppose, for instance, that when $A$ owns the asset her payoff is strictly 
concave in $a$ and maximized at a value greater or equal than $a^{*}$. In this case $A$ will never be tempted to invest less than $a^{*}$, even if $B$ were to refuse to exercise his option. Assumption 1(a) then suffices to achieve efficiency with an option contract. In particular, if investments are independent, i.e., if $v_{a b}(a, b)=0$, then it is always possible to achieve the first best with an option contract.

It also seems worthwhile to note that the logic of Proposition 2 does not hinge on the assumption that investments are one-dimensional. In particular, whenever it is the case that (i) $B$-ownership induces $B$ to invest efficiently given that $A$ has made her first best investment choice and $(i i) B$ does not invest under $A$-ownership, the option price can be set such that $B$ exercises his option to own if $A$ has invested efficiently and $A$ receives the first best surplus in this case. For all other investment choices $A$ receives strictly less than the first best surplus (since B gets at least zero), so efficiency can be achieved.

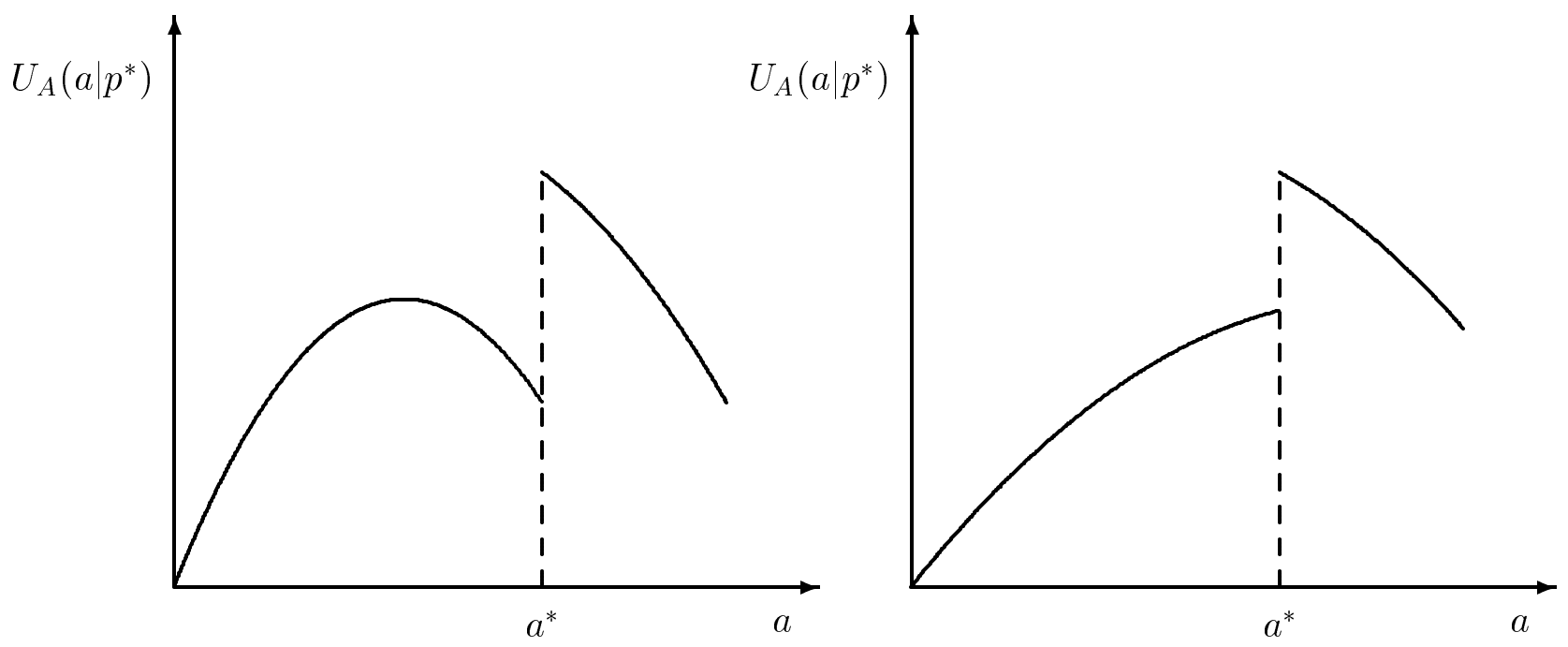

Figure 2: $A$ 's payoff function with an option contract

Figure 2 depicts $A$ 's payoff under the optimal option contract. Two cases are distinguished. In the left diagram investments are complements, so $A$ has an incentive to underinvest as long as she owns the asset and $B$ chooses $b=0$. In the right diagram investments are substitutes. Here $A$ would overinvest if she owns the asset and $b=0$. Note that there is a 
discontinuity at $a=a^{*}$ in both cases, resulting from the inefficient investment choice $B$ makes under A-ownership.

\section{Option contracts and renegotiation}

In the previous section we assumed that the two parties cannot renegotiate the initial contract. Suppose now that the parties will renegotiate whenever there is scope for an efficiency improvement. The only relevant time for renegotiation is between dates 1 and 2. After date 2 investments are sunk and every ownership structure will lead to an efficient use of the asset.

The possibility of renegotiation affects $A$ 's payoff under an option contract. Suppose that $A$ invested $a<a^{*}$. In this case both parties anticipate that $B$ will not exercise his option and therefore not invest, which is inefficient. Therefore, both parties have an incentive to renegotiate $p^{*}$ to a lower price such that $B$ is induced to buy the firm and to invest efficiently (given $a$ ). Thus, if $A$ gets some of the surplus of renegotiation, her payoff if she underinvests increases. A's payoff is unaffected by renegotiation only if $B$ has all the bargaining power in the renegotiation game.

To address this problem more formally, suppose that $B$ has the option to buy the asset from $A$ at price $p$ at date $2 \frac{1}{2}$, i.e. after both investments have been sunk. Consider first the case where $a$ is such that

$$
U^{B}\left(a, b^{*}(a) \mid B\right) \geq p
$$

In this case $B$ 's payoff if he invests efficiently (given $a$ ) and exercises his option at the current option price $p$ is higher than his payoff from not investing and not exercising the option. In particular, $A$ will refuse any offer by $B$ to obtain the ownership right at a price below $p$, since she knows that $B$ will find it in his own interest to exercise the option at price $p$ if renegotiation fails. Clearly, $B$ will refuse any offer to obtain the ownership right at a price above $p$. So in this case there is no scope for renegotiation and payoffs are determined by the initial option contract.

Consider now the case where $a$ is such that

$$
U^{B}\left(a, b^{*}(a) \mid B\right)<p
$$

If the option contract is not renegotiated between dates 1 and 2, Assumption 1(b) implies 
that final payoffs are given by $U^{A}(a, 0 \mid A)=v(a, 0) \Leftrightarrow a$ for $A$ and $U^{B}(a, 0 \mid A)=0$ for $B$. Assumption 1(a) implies that the additional surplus which can be generated by transfering the ownership right to $B$ is given by

$$
v\left(a, b^{*}(a)\right) \Leftrightarrow b^{*}(a) \Leftrightarrow v(a, 0)>0 .
$$

Suppose that the surplus from renegotiation is split between the two parties in proportion $(\hat{\lambda}, 1 \Leftrightarrow \hat{\lambda})$. It may well be that the allocation of bargaining power is the same in the renegotiation game as in the bargaining game at date 3, i.e. $\hat{\lambda}=\lambda$, but this is not necessary for our results. Then, given the initial contract with option price $p$ and $a$ satisfying (23), A's payoff as a function of her investment level is given by

$$
u^{A}(a)=(1 \Leftrightarrow \hat{\lambda}) v(a, 0)+\hat{\lambda} v\left(a, b^{*}(a)\right) \Leftrightarrow \hat{\lambda} b^{*}(a) \Leftrightarrow a
$$

Even though $A$ 's payoff with renegotiation differs from her payoff without renegotiation, efficiency can still be induced with the same option contract as in Proposition 2.

Proposition 3 An option contract that gives $B$ the right to buy the asset at price

$$
p^{*}=U^{B}\left(a^{*}, b^{*} \mid B\right)
$$

at date $2 \frac{1}{2}$ induces first best investment levels $\left(a^{*}, b^{*}\right)$ with renegotiation.

ProOF: The argument is almost the same as in the proof of Proposition 1 and we thus skip the details. Because the initial contract remains in place and $B$ exercises his option if $A$ invests $a^{*}, A$ obtains $S\left(a^{*}, b^{*}\right)$ if she invests $a^{*}$. $B$ can always guarantee himself a payoff of at least 0 by not investing, not exercising his option, and refusing to renegotiate. Hence, $A$ cannot get more than $S\left(a^{*}, b^{*}\right)$ and $a^{*}$ is again her uniquely optimal investment level. Q.E.D.

While Proposition 3 shows that an option contract still achieves the first best when renegotiation is possible, it is no longer clear that an option contract is required to achieve efficiency: the parties may simply agree to give $A$ the ownership right in the initial contract, anticipating that the ownership right will be transferred to $B$ through renegotation to ensure that $B$ invests efficiently (as he will do under Assumption 1(a)). If the price at which the 
ownership right is transferred reflects $A$ 's investment effort, this arrangement also provides investment incentives for $A$.

In particular, when $A$ has all the bargaining power in the renegotiation stage it is clearly in her interest to maximize the total surplus. If $\hat{\lambda}<1$ then $A$ will choose her initial investment to maximize a weighted average of the her threatpoint in the renegotation game (given by $v(a, 0) \Leftrightarrow a$, her payoff under $A$-ownership) and the surplus $S\left(a, b^{*}(a)\right)$ resulting from the transfer of the ownership right to $B$. As verified in the following proposition, this implies that if $A$ does not have all the bargaining power a transfer of the ownership right without an option contract implements first best investments if and only if A-ownership without renegotiation already ensures that $A$ chooses $a^{*}$. Note that this condition is satisfied if investments are independent, but fails if investments are either substitutes or complements.

Proposition 4 With renegotiation an initial contract specifying A-ownership induces first best investments if and only if either

(a) A has all the bargaining power in the renegatiation: $\hat{\lambda}=1$

or

(b) A-ownership without renegotiation induces $A$ to choose her efficient investment level: $U_{a}^{A}\left(a^{*}, 0 \mid A\right)=0$.

Proof: A's final payoff under $A$-ownership when she chooses $a$ is given by (25) which is equivalent to

$$
u^{A}(a)=(1 \Leftrightarrow \hat{\lambda})[v(a, 0) \Leftrightarrow a]+\hat{\lambda}\left[v\left(a, b^{*}(a)\right) \Leftrightarrow b^{*}(a) \Leftrightarrow a\right]=(1 \Leftrightarrow \hat{\lambda}) S(a, 0)+\hat{\lambda} S\left(a, b^{*}(a)\right) .
$$

Hence, by strict concavity of the surplus function, $a^{*}$ is the optimal choice for $A$ if and only if

$$
\hat{\lambda}\left[S_{a}\left(a^{*}, b^{*}\right)+S_{b}\left(a^{*}, b^{*}\right) b_{a}^{*}\left(a^{*}\right)\right]+(1 \Leftrightarrow \hat{\lambda}) S_{a}\left(a^{*}, 0\right)=0
$$

By efficiency $S_{a}\left(a^{*}, b^{*}\right)=S_{b}\left(a^{*}, b^{*}\right)=0$. Thus, $a^{*}$ is optimal if and only if

$$
(1 \Leftrightarrow \hat{\lambda}) S_{a}\left(a^{*}, 0\right)=(1 \Leftrightarrow \hat{\lambda}) U_{a}^{A}\left(a^{*}, 0 \mid A\right)=0,
$$

implying the result.

Q.E.D. 
So far we have assumed that $B$ is given the right to exercise his option at date $2 \frac{1}{2}$, i.e., after both investments have been made. Clearly, it is important that $B$ exercises his option after he observed $A$ 's investment level. But does it matter whether $B$ exercises his option before or after he invests himself? If there is no renegotiation the timing of the option does not matter: After $A$ made his investment it is only $B$ who has to take relevant decisions, and it makes no difference to him whether he invests first and then exercises the option or the other way round.

With renegotiation, however, the timing of the option is important. To see this, consider the option contract of Proposition 3 and suppose that $A$ did invest efficiently. If the exercise date of the option is at date $2 \frac{1}{2}$, there is nothing to renegotiate. In particular, $B$ cannot credibly threaten not to exercise his option if $A$ is not willing to reduce the option price, since it is optimal for him to exercise his option anyway. Thus, $A$ can simply refuse to bargain over the option price. Suppose now that the exercise date of the option is at date $1 \frac{1}{2}$ with the option price remaining at $p^{*}$ and that renegotiation is possible between dates $1 \frac{1}{2}$ and 2 . In this case it is optimal for $B$ not to exercise the option at date $1 \frac{1}{2}$, even if $A$ invested efficiently: exercising the option gives $B$ a payoff of zero, whereas the renegotiation taking place after $B$ refused to exercise his option provides $B$ with a strictly positive payoff. This implies that $A$ 's payoff when she invests $a^{*}$ is reduced, which distorts her investment incentives. It is easy to see that the option contract of Proposition 3 then no longer implements the first best.

The following Proposition shows under what conditions the first best can be achieved with an option contract that gives $B$ the right to buy the asset at date $1 \frac{1}{2}$. We restrict attention to cases that are not covered by Proposition 4. Let $\bar{a}=\arg \max v(a, 0) \Leftrightarrow a$ denote $A$ 's optimal investment level if she owns the asset, where $\bar{a}$ is uniquely characterized by $v_{a}(\bar{a}, 0)=1$. If $\bar{a}=a^{*}$ or $\hat{\lambda}=1$, we know by Proposition 4 that the first best can be implemented by simple $A$-ownership that is renegotiated to $B$-ownership, so we exclude these cases here.

Proposition 5 Let $\hat{\lambda}<1$. If $\bar{a}<a^{*}$ then there exists no option contract $p$ which gives $B$ the right to buy the asset at date $1 \frac{1}{2}$ that induces $A$ to invest efficiently. If $\bar{a}>a^{*}$, then an option which gives $B$ the right to buy the asset at date $1 \frac{1}{2}$ at price

$$
\hat{p}=U^{B}\left(a^{*}, b^{*} \mid B\right) \Leftrightarrow(1 \Leftrightarrow \hat{\lambda})\left[S\left(a^{*}, b^{*}\right) \Leftrightarrow S\left(a^{*}, 0\right)\right]
$$


induces both parties to invest efficiently.

Proof: See the Appendix.

Proposition 5 says that if the exercise date of the option is at date $1 \frac{1}{2}$, then an option contract can be used to implement the first best only if $A$ has an incentive to overinvest if she owns the asset unconditionally. This condition is satisfied if investments are substitutes, but fails when they are complements.

To give some intuition for the proof of Proposition 5, note that any option contract with an exercise date $1 \frac{1}{2}$ will be exercised by $B$ if and only if $B$ 's payoff from exercising the option and investing efficiently is larger than $B$ 's share of the surplus in the renegotiation game when $A$ is the owner of the asset. Formally,

$$
U^{B}\left(a, b^{*}(a) \mid B\right) \Leftrightarrow p \geq(1 \Leftrightarrow \hat{\lambda})\left[v\left(a, b^{*}(a)\right) \Leftrightarrow b^{*}(a) \Leftrightarrow v(a, 0)\right]
$$

is a necessary and sufficient condition for $B$ to exercise the option. This condition can be rewritten as

$$
U^{B}\left(a, b^{*}(a) \mid B\right) \Leftrightarrow(1 \Leftrightarrow \hat{\lambda})\left[S\left(a, b^{*}(a)\right) \Leftrightarrow S(a, 0)\right] \geq p .
$$

As the proof of Proposition 5 shows, the left hand side of this inequality is strictly increasing in $a$. Hence, the option price which provides $B$ with the appropriate incentive to exercise his option if and only if $a \geq a^{*}$ is given by $\hat{p}$. Note that $\hat{p}$ differs from the $p^{*}$ employed in Propositions 2 and 3.

The problem with this contract is that at $a=a^{*} A$ is just indifferent whether $B$ exercises his option or not, i.e., $A$ 's payoff function is continuous at $a=a^{*}$. Hence the contract will fail to induce the first best whenever $A$ 's optimal choice given $A$-ownership is less than $a^{*}$. This is illustrated in Figure 3. 


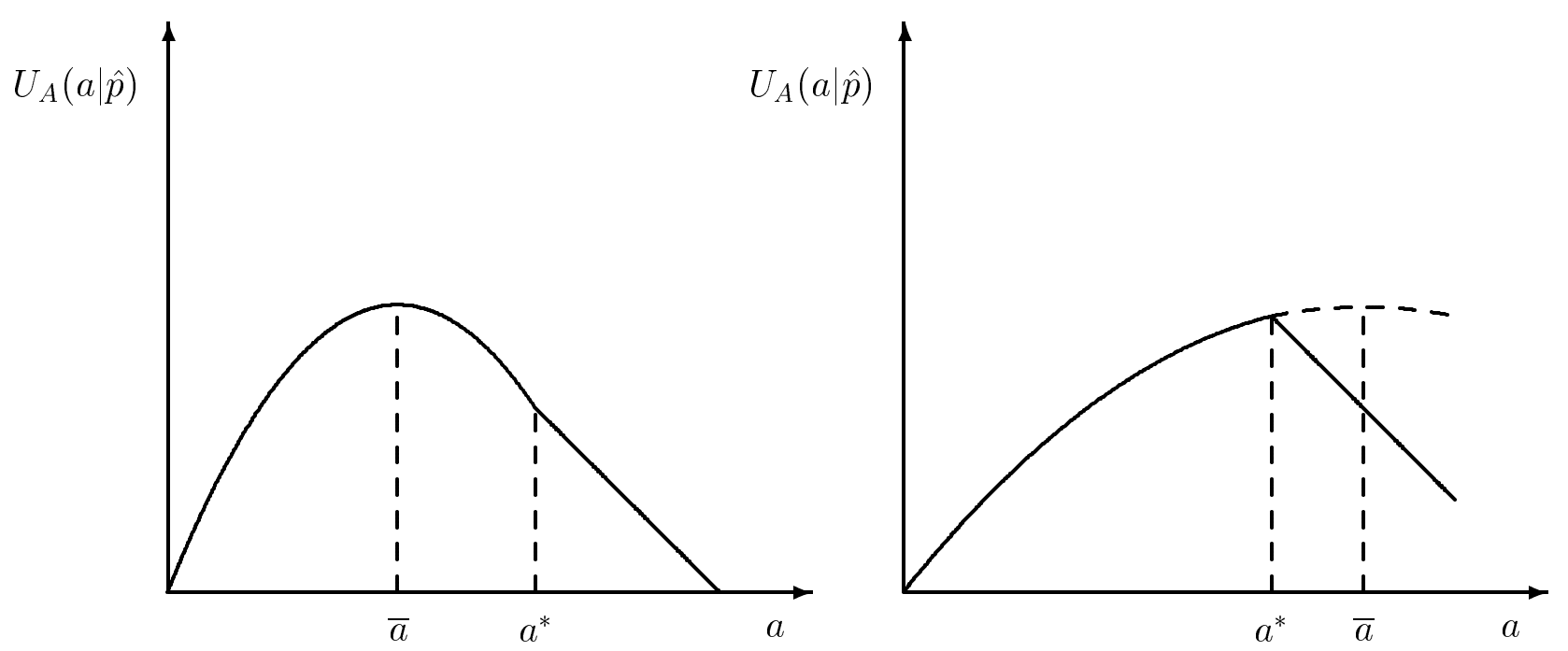

Figure 3: $A$ 's payoff if $B$ exercises at date $1 \frac{1}{2}$

If the exercise date of the option is after $A$ but before $B$ invested, $B$ can extract some of the surplus from $A$ if he can commit not to exercise his option, which may in turn distort A's investment incentives. As mentioned already in the Introduction, this problem has been observed independently by Edlin and Hermalin (1997). They conclude from this observation that an option contract can implement the first best if and only if investments are substitutes at the margin, i.e., if $\bar{a} \geq a^{*}$ in our model. Our interpretation of this observation is different. We would like to stress that the timing of the option is of crucial importance. If the exercise date of the option can be delayed until after $B$ has to invest, then $B$ cannot commit not to exercise the option and our Proposition 3 applies. One way to do this is to give $B$ an American call option with an expiration date very far in the future (e.g. after date 3). Since an American call option can be exercised anytime before the expiration date, $B$ will exercise it at some point between dates 1 and 3, but he cannot commit not to exercise it before he himself invested.

A potential problem arises if $B$ can sell or burn his option publicly at date $1 \frac{1}{2}$ in order to commit himself not to exercise it. This problem could be solved by making the option to buy the firm inalienable and by depositing the contract with a third party such as a notary. The role of the notary is only to prevent a unilateral deviation from the contract, such as burning 
or selling the option. It is important to note, however, that we do not need the third party to prevent renegotiation if there is scope for an efficiency improvement and both parties want to renegotiate (as has been shown by Proposition 3).

There is an alternative (perhaps more elegant) solution to this problem that does not rely on third parties: Suppose that $B$ has to pay $p^{*}$ to $A$ at date 0 already. The option contract gives $B$ the right either to become the owner of the asset or to get back $p^{*}$ from $A$ at date $2 \frac{1}{2}$. Clearly, $B$ does not want to burn this contract because he paid $p^{*}$ upfront already. Furthermore, this contract is nothing but a convertible debt contract: $B$ gives a credit $p^{*}$ to $A$ and has the option to either get back his money or to receive an equity stake in the asset. This solution requires that the option can only be exercised after $B$ has made his investment decision. Otherwise $B$ has an incentive to insist on getting back $p^{*}$ before he himself invested.

A closely related issue is the timing of the investments. Suppose that both parties can invest over time and that they do have some discretion in when to invest how much. We clearly need that there is some final date (date 3 in our model) after which no further investments are possible. Furthermore, we have to make sure (through the timing of the option as discussed above) that $B$ cannot delay his investment until after his option expired. But except for this, endogenous timing of the investments does not seem to be problematic: Because $A$ gets all of the surplus if she invests first and chooses $a^{*}$ she has no incentive to delay her investment. Furthermore, $B$ cannot gain from leap-frogging $A$ and investing before she invests. It clearly would not pay to invest more than $b^{*}$. If he invests less than $b^{*}$, then, after $A$ invested $a^{*}$, $B$ will make an additional investement and increase his total investment up to $b^{*}$. Thus, $B$ cannot gain from the different timing either.

\section{Uncertainty}

An important question is whether the efficiency properties of option contracts are affected if there is some uncertainty. So far our model has been fully deterministic. Given the optimal contract, $B$ is just indifferent whether or not to exercise his option given that $A$ invested efficiently. Thus, it may seem that our result characterizes a knife-edge case and breaks down as soon as there is some uncertainty about the surplus to be generated. In this section we are going to show that this is not the case. A properly designed option contract continues to give 
first best investment incentives as long as the uncertainty is sufficiently small.

Note first that any uncertainty that resolves after $B$ 's option has been exercised does not affect our results. We can simply replace the surplus $v(a, b)$ with its expected value. Nor does any uncertainty matter that resolves before $A$ 's investment took place. In this case the parties can renegotiate the initial contract after the resolution of the uncertainty but before $A$ invested in order to restore efficiency. Thus, we can restrict attention to the case where the state of the world materializes between dates 1 and $2 \frac{1}{2}$.

We model this as follows: the surplus is stochastic and given by

$$
\tilde{v}(a, b)=v(a, b)+\tilde{\theta}
$$

where $\tilde{\theta}$ is a random variable and $v(a, b)$ satisfies our previous assumptions. Since $\tilde{\theta}$ is an additive term that is independent of the investments it simply accrues to whoever owns the asset at date 3 . Hence, final payoffs are given by the random variables $\tilde{U}^{i}(a, b \mid i)=U^{i}(a, b \mid$ $i)+\tilde{\theta}$ and $\left.\tilde{U}^{i}(a, b \mid j)=U^{i}(a, b) \mid j\right), i, j \in\{A, B\}, i \neq j$, where $U^{i}(a, b \mid i)$ is the final payoff of the party who owns the asset at date 3 if there is no uncertainty.

The random variable $\tilde{\theta}$ is drawn from $[0, \hat{\theta}]$ according to a density $f(\theta \mid \hat{\theta})$. The assumption that $\tilde{\theta} \geq 0$ is for notational convenience and does not affect our result (But see the remark at the end of this section). The density is parameterized by $\hat{\theta}$ because we want to vary the amout of uncertainty by varying the support of $\tilde{\theta}$. More specifically, let $g$ be a strictly positive density defined on the unit interval. We then let

$$
f(\theta \mid \hat{\theta})=\frac{1}{\hat{\theta}} g\left(\frac{\theta}{\hat{\theta}}\right)
$$

Thus, if $\hat{\theta}$ is reduced, the probabilty mass is squeezed proportionally in a smaller interval.

Suppose for concreteness that $\tilde{\theta}$ is realized between dates 1 and 2, i.e., before $B$ 's investment took place. ${ }^{17}$ The following proposition shows that the same option contract that we used in the deterministic case implements the first best with uncertainty if the amount of uncertainty is sufficiently small.

\footnotetext{
${ }^{17} \mathrm{~A}$ very similar argument can be given for the case where the uncertainty resolves after date 2 but before $B$ has to exercise his option.
} 
Proposition 6 Let $\hat{\lambda}<1$. Then there exists $\bar{\theta}>0$ such that for all $\hat{\theta}<\bar{\theta}$ an option contract that gives $B$ the right to buy the asset at price

$$
p^{*}=U^{B}\left(a^{*}, b^{*} \mid B\right)
$$

at date $2 \frac{1}{2}$ induces first best investment levels $\left(a^{*}, b^{*}\right)$ with renegotiation.

Proof: See the Appendix.

The intuition for this result can be summarized as follows. Before $B$ has to make his investment decision, he observes the realization $\theta$. Given the option price $p^{*}$ it is optimal for him to invest efficiently and to exercise the option without renegotiation if and only if

$$
U^{B}\left(a, b^{*}(a) \mid B\right)+\theta \geq p^{*}
$$

Thus, since $\theta \geq 0, B$ will do so with strictly positive probability even if $A$ invested slightly less that $a^{*}$. Does this give an incentive to $A$ to shirk on her investment? Consider first a local deviation from $a^{*}$. Recall, that in the deterministic case there is a discontinuity in $A$ 's payoff function at $a=a^{*}$, so a marginal reduction of $a$ below $a^{*}$ reduces $A^{\prime}$ 's utility by an amount that is bounded away from 0. In the stochastic case, a marginal reduction of $a$ below $a^{*}$ yields a marginal change in her expected payoff function. However, if the amount of the uncertainty is sufficiently small, the left-hand derivative of the expected payoff function is strictly positive at $a^{*}$. This guarantees a local maximum at $a^{*}$.

But it could also be the case that $A$ has an incentive to invest substantially less than $a^{*}$. The reason is that only by underinvesting $A$ receives a part of the expected payoff $E(\tilde{\theta} \mid \hat{\theta})>0$ which accures to $B$ if $A$ invests efficiently. This additional payoff makes it more attractive for her to invest too little. However, if $\hat{\theta}$ is sufficiently small, $E(\tilde{\theta} \mid \hat{\theta})$ is small and a deviation does not pay for $A$. Figure 4 illustrates $A$ 's expected payoff as a function of $a$. The dashed line is the payoff function in the deterministic case. 


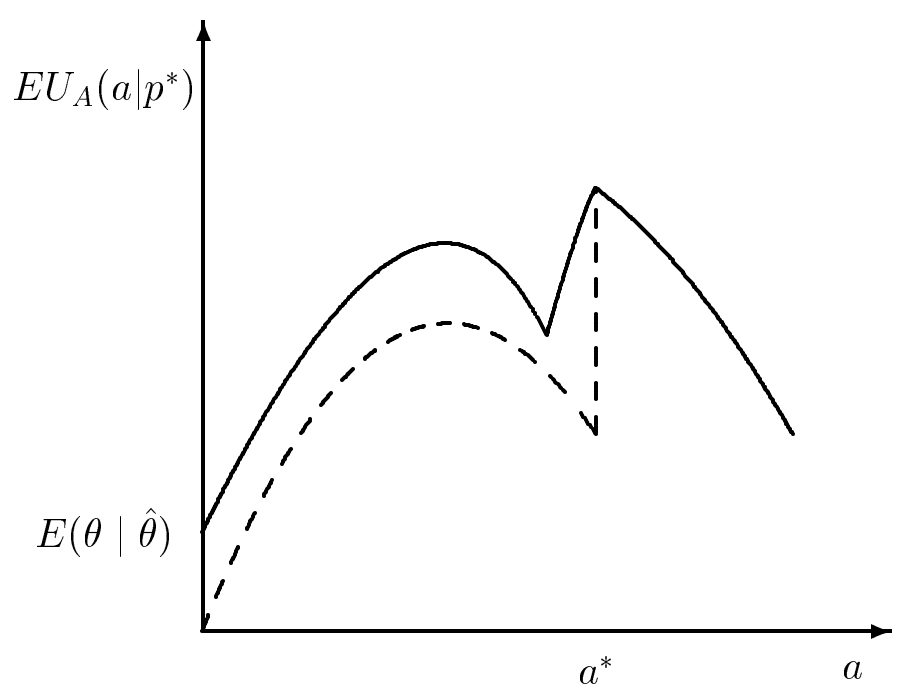

Figure 4: $A$ 's expected payoff function with uncertainty

Note that if there is no renegotiation the underlying discontinuity in $A$ 's payoff function is even larger as compared to the case with renegotiation. Hence, the result of Proposition 6 holds for the case without renegotiation as well.

The option price in Proposition 6 is exactly the same as the one we used in Propositions 2 and 3. This is due to our assumption that the lower bound of the support of $\theta$ is zero. If $\tilde{\theta}$ is distributed in some interval $[\underline{\theta}, \bar{\theta}]$, the option price would have to be chosen such that

$$
p^{*}=U^{B}\left(a^{*}, b^{*}\right) \Leftrightarrow \underline{\theta},
$$

i.e., $p^{*}$ has to be chosen such that $B$ exercises his option with probability 1 if $A$ invests efficiently.

\section{Conclusions}

The paper has shown that contingent ownership structures can induce both parties to invest efficiently in many interesting cases. This provides one explanation for the prevalent use of options-to-own, such as warrants and convertible securities, in joint ventures. The main assumptions we employed are (i) that the two parties invest sequentially, (ii) that the second 
party can be induced to invest efficiently by giving him the ownership right on the asset (Assumption 1(a)), and (iii) the second party does not invest if the first party owns the asset (Assumption 1(b)). The later two assumptions are satisfied if both parties invest in physical capital, but also if the human capital component of the second party's investment or her bargaining power are sufficiently low.

As we have noted in Section 3, Assumption 1(b) is much stronger than needed. What about Assumption 1(a)? It guarantees that $B$ invests efficiently if he owns the asset. In the model with renegotiation this assumption can be relaxed. Suppose that, being the owner, $B$ has an incentive to overinvest. In this case the initial option contract could be renegotiated after $A$ invested to another option contract that now gives $A$ the right to buy the firm at a set price after $B$ invested. This renegotiated contract will ensure that $B$ chooses the conditionally optimal investment level. However, $A$ will no longer receive the first best surplus if she chooses $a^{*}$, making it much more difficult to characterize the conditions under which an appropriately designed initial option contract achieves the first best.

Some further extensions of our analysis should be possible. For instance, Proposition 6 only deals with the case where the amount of uncertainty is "small". We conjecture that it is possible to use an option contract to achieve the first best even when the construction in Proposition 6 fails because $a^{*}$ is no longer a local maximum of $A$ 's payoff function under the option price $p^{*}$. The idea is to raise the option price to improve $A$ 's marginal investment incentives. Note that with such a higher option price renegotiation becomes crucial to achieve efficiency, since it is no longer the case that $B$ always exercises the option without renegotiation if $A$ has invested efficiently. While this effect is interesting, it further complicates the analysis of the uncertainty case and so far we have not been able to determine explicit conditions on the underlying functions which guarantee that the first best can be achieved with an option price different from $p^{*}$.

While our analysis has shown that option contracts on ownership rights are a versatile tool to achieve efficency, we have not touched upon the interesting issue of characterizing optimal ownership structures when option contracts do not implement the first best. It is clear that option contracts will improve on unconditional ownership structures in much broader circumstances then the one considered here. For example, a simple option contract may be 
a useful device in a joint venture even when investment decisions are taken simultansously. However, in these cases other contractual arrangements may perform even better. Finally, it should be noted that the options used in venture capital contracts very often are options on a fraction of a firm's equity (as in the Arcor example described in the Introduction). Our simplified model provides no explanation of this fact which we hope to address in future research.

\section{Appendix}

Proof OF Proposition 5: Consider an option contract with exercise price $p$. By Assumption $1, B$ will exercise his option if and only if

$$
U^{B}\left(a, b^{*}(a) \mid B\right) \Leftrightarrow p \geq(1 \Leftrightarrow \hat{\lambda})\left[S\left(a, b^{*}(a)\right) \Leftrightarrow S(a, 0)\right]
$$

Note that ex post efficiency implies that $U^{B}\left(a, b^{*}(a) \mid B\right)+U^{A}\left(a, b^{*}(a) \mid B\right)=S\left(a, b^{*}(a)\right)$. Hence, given $B$ 's optimal exercise decision (and subsequent optimal investment decision), A's payoff from investing $a$ is given by

$$
u^{A}(a, p)=\min \left\{U^{A}\left(a, b^{*}(a) \mid B\right)+p,(1 \Leftrightarrow \hat{\lambda}) S(a, 0)+\hat{\lambda} S\left(a, b^{*}(a)\right)\right\} .
$$

A maximum of $u^{A}(a, p)$ with respect to $a$ must then correspond to one of the following cases:

(i) an investment level which maximizes the first function on the right hand side - which is $A^{\prime} s$ optimal investment choice when $B$ owns the asset and which is different from $a^{*}$ by Proposition 1

(ii) an investment choice which maximizes the second function on the right hand side - which is $A^{\prime} s$ optimal investment choice when $A$ owns the asset initially and renegation without an option contract transfers the ownership right to $B$ and which is different from $a^{*}$ by Proposition 4

(iii) an investment level, where both functions on the right hand side obtain the same value.

Hence, a necessary condition for $a^{*}$ to be a solution to $A$ 's maximization problem is that the option price $p$ satisfies

$$
p=(1 \Leftrightarrow \hat{\lambda}) S\left(a^{*}, 0\right)+\hat{\lambda} S\left(a^{*}, b^{*}\right) \Leftrightarrow U^{A}\left(a^{*}, b^{*} \mid B\right) \Leftrightarrow p=\hat{p} .
$$


Given the option price $\hat{p}, A^{\prime}$ 's payoff when she invests $a^{*}$ is

$$
u^{A}\left(a^{*}, \hat{p}\right)=U^{A}\left(a^{*}, b^{*} \mid B\right)+\hat{p}=(1 \Leftrightarrow \hat{\lambda}) S\left(a^{*}, 0\right)+\hat{\lambda} S\left(a^{*}, b^{*}\right) .
$$

We next show that $A$ never overinvest. That is, $u^{A}(a, \hat{p})<u^{A}\left(a^{*}, \hat{p}\right)$ for all $a>a^{*}$. From (A2) it suffices to show that $U^{A}\left(a, b^{*}(a) \mid B\right)$ is strictly decreasing in $a$ for $a \geq a^{*}$. To do so, note that the surplus function $S\left(a, b^{*}(a)\right.$ ) is strictly decreasing in $a$ for $a \geq a^{*}$ (by strict concavity of the surplus function) and that $U^{B}\left(a, b^{*}(a) \mid B\right)$ is strictly increasing in $a$ for all a. Since $U^{A}\left(a, b^{*}(a) \mid B\right)=S\left(a, b^{*}(a)\right) \Leftrightarrow U^{B}\left(a, b^{*}(a) \mid B\right)$ the result follows.

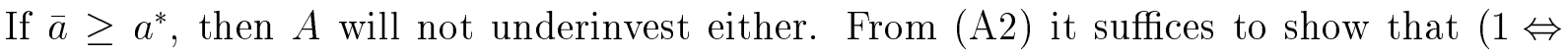
$\hat{\lambda}) S(a, 0)+\hat{\lambda} S\left(a, b^{*}(a)\right)$ is strictly increasing in $a$ for $a \leq a^{*}$. This, however, is immediate from the strict concavity of the surplus function and the condition $S_{a}(\bar{a}, 0)=0$.

To see that the condition $\bar{a} \geq a^{*}$ is also necessary for $\hat{p}$ to induce efficient investments, it remains to note that if the condition fails both functions in the minimum defining $A$ 's payoff are strictly decreasing in $a$ at $a^{*}$, implying that the minimum of the two is also strictly decreasing, allowing us to conclude that $A$ can increase his payoff by choosing $a<a^{*}$. Q.E.D.

Proof of Proposition 6: Given $p^{*}, B$ will exercise his option if and only if

$$
U^{B}\left(a, b^{*}(a) \mid B\right)+\theta \geq p^{*}
$$

where $\theta$ is a realization of $\tilde{\theta}$. The left hand side is strictly increasing with $a$. Thus, if $a \geq a^{*}$, $B$ exercises his option for all realizations of $\tilde{\theta}$ without renegotiation. Furthermore, it is never optimal for $A$ to choose $a>a^{*}$.

Now consider $a \leq a^{*}$. Define

$$
\theta(a, \hat{\theta})=\min \left\{\hat{\theta}, p^{*} \Leftrightarrow U^{B}\left(a, b^{*}(a) \mid B\right)\right\}
$$

If $\theta \geq \theta(a, \hat{\theta})$ there is no renegotiation because $B$ exercises his option anyway. If $\theta<\theta(a, \hat{\theta})$ renegotiation is necessary to induce $B$ to buy the asset and to invest efficiently. The surplus of renegotiation is given by $(24)$ and is shared in proportion $(\hat{\lambda}, 1 \Leftrightarrow \hat{\lambda})$ by the two parties. Thus, 
in expected terms $A^{\prime}$ 's payoff if she chooses $a \in\left[0, a^{*}\right]$ is given by

$$
\begin{aligned}
u^{A}(a, \hat{\theta})= & \int_{0}^{\theta(a, \hat{\theta})}\left[(1 \Leftrightarrow \hat{\lambda}) S(a, 0)+\hat{\lambda} S\left(a, b^{*}(a)\right)+\theta\right] f(\theta \mid \hat{\theta}) d \theta \\
& +\int_{\theta(a, \hat{\theta})}^{\theta \hat{\theta}}\left[p^{*}+U^{A}\left(a, b^{*}(a) \mid B\right)\right] f(\theta \mid \hat{\theta}) d \theta .
\end{aligned}
$$

In particular, we have $u^{A}\left(a^{*}, \hat{\theta}\right)=S\left(a^{*}, b^{*}\right)$ for all $\hat{\theta}$. Now let

$$
\underline{a}(\hat{\theta})=\inf \{a \mid \theta(a, \hat{\theta})<\hat{\theta}\}<a^{*} .
$$

If $a<\underline{a}(\hat{\theta}), B$ will never exercise his option. In this case $A$ 's payoff is given by

$$
(1 \Leftrightarrow \hat{\lambda}) S(a, 0)+\hat{\lambda} S\left(a, b^{*}(a)\right)+E[\tilde{\theta} \mid \hat{\theta}]<(1 \Leftrightarrow \hat{\lambda}) S(a, 0)+\hat{\lambda} S\left(a^{*}, b^{*}\right)+\hat{\theta} .
$$

We want to find an upper bound for $\hat{\theta}$ so that the right-hand side of (A9) is smaller than $S\left(a^{*}, b^{*}\right)$ which is $A^{\prime}$ 's payoff if she invests $a^{*}$. Note that

$$
S\left(a^{*}, b^{*}\right) \Leftrightarrow \max _{a \leq a^{*}} S(a, 0)>0
$$

Hence, for all $\hat{\theta}<(1 \Leftrightarrow \hat{\lambda})\left[S\left(a^{*}, b^{*}\right) \Leftrightarrow \max _{a \leq a^{*}} S(a, 0)\right]$ we have

$$
\forall a<\underline{a}(\hat{\theta}): u^{A}(a, \hat{\theta})<u^{A}\left(a^{*}, \hat{\theta}\right)
$$

implying that $A$ 's optimal choice lies in the interval $\left[\underline{a}(\hat{\theta}), a^{*}\right]$.

To finish the proof it then suffices to show that there exist $\bar{\theta}>0$ such that the derivative of $A$ 's payoff function satisfies

$$
\hat{\theta} \in(0, \bar{\theta}), a \in\left(\underline{a}(\hat{\theta}), a^{*}\right) \Rightarrow u_{a}^{A}\left(a^{*}, \hat{\theta}\right)>0 .
$$

Note that $a \in\left(\underline{a}(\hat{\theta}), a^{*}\right)$ implies $\theta(a, \hat{\theta})=p^{*} \Leftrightarrow U^{B}\left(a, b^{*}(a) \mid B\right)$. Take the derviative of $u^{A}(a, \hat{\theta})$ given in $(\mathrm{A} 7)$ and use the identities $p^{*}+U^{A}\left(a, b^{*}(a) \mid B\right)=S\left(a, b^{*}(a)\right)+\theta(a, \hat{\theta})$ and $\left.d \theta(a, \hat{\theta}) / d a=\Leftrightarrow U_{a}^{B}\left(a, b^{*}(a) \mid B\right)\right)$ to obtain

$$
\begin{aligned}
u_{a}^{A}(a, \hat{\theta})=(1 & \Leftrightarrow \hat{\lambda})\left[S\left(a, b^{*}(a)\right) \Leftrightarrow S(a, 0)\right] U_{a}^{B}\left(a, b^{*}(a) \mid B\right) \cdot f(\theta(a, \hat{\theta}) \mid \hat{\theta}) \\
& +\int_{0}^{\theta(a, \hat{\theta})}\left[(1 \Leftrightarrow \hat{\lambda}) S_{a}(a, 0)+\hat{\lambda} S_{a}\left(a, b^{*}(a)\right)\right] f(\theta \mid \hat{\theta}) d \theta \\
& +\int_{\theta(a, \hat{\theta})}^{\hat{\theta}} U_{a}^{A}\left(a, b^{*}(a) \mid B\right) f(\theta \mid \hat{\theta}) d \theta .
\end{aligned}
$$


In this expression, the terms in the second and third line are bounded below (by -1 and $\min _{a \in\left[0, a^{*}\right]} U_{a}^{A}\left(a, b^{*}(a)\right)$, respectively). The term multiplying $f(\theta(a, \hat{\theta}) \mid \hat{\theta})$ in the first line is strictly positive for $a$ sufficiently close to $a^{*}$. Because $\lim _{\hat{\theta} \rightarrow 0} \underline{a}(\hat{\theta})=a^{*}$ and $\lim _{\hat{\theta} \rightarrow 0} \min _{a \in\left[\underline{a}(\hat{\theta}), a^{*}\right]} f(\theta(a, \hat{\theta}) \mid \hat{\theta})=\infty$ the result in (A12) follows. Q.E.D. 


\section{References}

Aghion, P., Dewatripont, M. and Rey, P. "Renegotiation Design with Unverifiable Information." Econometrica, Vol. 62 (1994), pp. 257-282.

Che, Y.-K. And Hausch, D. "Cooperative Investments and the Value of Contracting: Coase vs. Williamson." Mimeo, University of Wisconsin-Madison, 1996.

Chung, T.-Y. "Incomplete Contracts, Specific Investments and Risk Sharing." Review of Economic Studies, Vol. 58 (1991), pp. 1031-1042.

Dearden, J.A. And Klotz, D. "Investment Timing and Efficiency in Incomplete Contracts." Mimeo, Lehigh University, 1995.

De Fraja, G. "After You Sir. Sequential Investment as a Solution to the Hold-Up Problem." Mimeo, University of York, 1995.

Demski, J.S. and Sappington, D.E.M. "Resolving Double Moral Hazard Problems with Buyout Agreements." RAND Journal of Economics, Vol. 22 (1991), pp. 232-240.

Edlin, A.S. And Hermalin, B.E. "Contract Renegotiation in Agency Problems." Mimeo, University of California at Berkeley, 1997.

And Reichelstein, S. "Holdups, Standard Breach Remedies, and Optimal Investment." American Economic Review, Vol. 86 (1996), pp. 478-501.

Grossman, S. and Hart, O. "The Costs and Benefits of Ownership: a Theory of Vertical and Lateral Integration." Journal of Political Economy, Vol. 94 (1986), pp. 691-719.

Hart, O. Firms, Contracts, and Financial Structure. Oxford: Clarendon Press, 1995.

AND Moore, J. "Incomplete Contracts and Renegotiation." Econometrica, Vol. 56 (1988), pp. $755-785$.

AND — "Property Rights and the Nature of the Firm." Journal of Political Economy, Vol. 98 (1990), 1119-1158.

Hermalin, B. and Katz, M. "Judicial Modification of Contracts Between Sophisticated Parties: A More Complete View of Incomplete Contracts and Their Breach." Journal 
of Law, Economics and Organization, Vol. 9 (1993), pp. 230-255.

Maskin, E. And Tirole, J. "Unforeseen Contingencies, Property Rights, and Incomplete Contracts." Mimeo, Harvard University, 1996.

Nöldeke, G. And Schmidt, K. "Option Contracts and Renegotiation: A Solution to the Hold-Up Problem." RAND Journal of Economics, Vol. 26 (1995), 163-179.

AND "Debt as an Option to Own in the Theory of Ownership Rights." In: A. Picot and E. Schlicht, eds., Firms, Markets, and Contracts: Contributions to Neoinstitutional Economics. Heidelberg: Physica, 1996.

Sahlman, W. "The Structure and Governance of Venture-Capital Organizations." Journal of Financial Economics, Vol. 27 (1990), pp. 473-521.

Tirole, J. "Incomplete Contracts: Where Do We Stand?" Mimeo, IDEI, Toulouse, 1994. 